\title{
Dietary micronutrients are associated with higher cognitive function gains among primary school children in rural Kenya
}

\author{
Constance A. Gewa ${ }^{1}$, Robert E. Weiss ${ }^{2}$, Nimrod O. Bwibo ${ }^{3}$, Shannon Whaley $^{4}$, Marian Sigman $^{4}$, \\ Suzanne P. Murphy ${ }^{5}$, Gail Harrison ${ }^{6}$ and Charlotte G. Neumann ${ }^{7}$ \\ ${ }^{1}$ Department of Global and Community Health, College of Health and Human Services, George Mason University, Fairfax, \\ VA 22030, USA \\ ${ }^{2}$ Department of Biostatistics, School of Public Health, University of California, Los Angeles, CA 90095, USA \\ ${ }^{3}$ School of Medicine, University of Nairobi, Nairobi, Kenya \\ ${ }^{4}$ Departments of Psychiatry and Psychology, Neuropsychiatry Institute, University of California, Los Angeles, CA 90095, USA \\ ${ }^{5}$ Cancer Research Center of Hawaii, University of Hawaii, 1236 Lauhala Street, Suite 407, Honolulu, HI 96813, USA \\ ${ }^{6}$ Department of Community Health Sciences, School of Public Health, University of California, Los Angeles, CA 90095, USA \\ ${ }^{7}$ Departments of Community Health Sciences and Pediatrics, Schools of Public Health and Medicine, University of California, \\ Los Angeles, CA 90095, USA
}

(Received 12 October 2007 - Revised 12 August 2008 - Accepted 12 August 2008 - First published online 30 September 2008)

\begin{abstract}
With the exception of iodine and $\mathrm{Fe}$, there is still very limited information on the effect of micronutrients on cognitive function, especially among school-age children. The present analysis evaluates the relationship between dietary Fe, $\mathrm{Zn}$ and B vitamins $\left(\mathrm{B}_{12}\right.$, $\mathrm{B}_{6}$, folate and riboflavin) and gains in cognitive test scores among school children in rural Kenya. Data for the present study were obtained from The Child Nutrition Kenya Project, a 2-year longitudinal, randomised controlled feeding intervention study using animal source foods. Dietary nutrient values were based on monthly and bimonthly $24 \mathrm{~h}$ recall data collected during the study period. In longitudinal regression analyses, available Fe, available $\mathrm{Zn}$, vitamin $\mathrm{B}_{12}$ and riboflavin showed significant relationships with improved cognitive test scores, after controlling for confounders such as energy intake, school, socio-economic status and morbidity. Available Fe intake was associated with significantly higher gains in Raven's Coloured Progressive Matrices test scores over time. Available $\mathrm{Zn}$ intake was associated with significantly higher gains in digit span-total test scores over time, while vitamin $\mathrm{B}_{12}$ and riboflavin intakes were each associated with significantly higher gains in digit span-forward test scores over time. This analysis demonstrates the influence of improved dietary micronutrient status on school children's cognitive function.
\end{abstract}

Dietary micronutrients: School children: Cognitive gains: Kenya

Except for iodine and $\mathrm{Fe}^{(1-4)}$, there is limited information available regarding the effect of other micronutrients on cognitive function, especially among school-age children in less-developed parts of the world. A number of intervention trials among anaemic and Fe-deficient but non-anaemic school-age children and adolescents have demonstrated positive impacts of Fe treatment on cognitive abilities, with studies reporting improvements in different functions including problem solving, concentration and intelligence ${ }^{(5-8)}$. The link between Fe deficiency and cognitive ability may be mediated by pathways such as ATP production, alterations in dopaminergic function, myelination and hippocampus structure and function $^{(9-15)}$. The hippocampus has been associated with memory functions while the dopaminergic system has in addition to memory been associated with learning, attention and motor control ${ }^{(16-18)}$. In addition, most children with $\mathrm{Fe}$ deficiency tend to come from deprived environments with inadequate nutrient intake, frequent illnesses, limited caregiver knowledge of optimal ways to care for the children along with deprivation of stimulation ${ }^{(3,19-21)}$, all of which may influence physical and mental development. There are relatively fewer studies on $\mathrm{Zn}$ and cognition. Most animal trials have shown a positive impact of $\mathrm{Zn}$ supplementation on functions such as learning, knowledge retention, attention, play and functional activity ${ }^{(2)}$, implicating $\mathrm{Zn}$ in some learning and recall abilities. Human studies on the other hand have shown inconsistent results between $\mathrm{Zn}$ and cognitive function, with some studies showing no measured positive impact on cognitive function $^{(23,24)}$ and one study showing some impact only in the presence of other nutrients ${ }^{(25)}$. Recent trials have shown that $\mathrm{Zn}$ concentration in the hippocampal formation is especially sensitive to dietary $\mathrm{Zn}^{(26-28)}$, with $\mathrm{Zn}$-deficient

Abbreviations: ASF, animal source foods; CNP, Child Nutrition Project; DS, digit span; ENGKG, energy intake per kg body weight; HAZ score, height-for-age $z$ score; RCPM, Raven's Coloured Progressive Matrices; SES, socio-economic status.

* Corresponding author: Dr Constance A. Gewa, fax +1 703993 1908, email cgewa@gmu.edu 
diets being associated with decreased hippocampal $\mathrm{Zn}$ content and impaired learning ability among adult rats ${ }^{(26)}$ and shortterm memory deficits among young and juvenile rats ${ }^{(28)}$.

$B$ vitamins may affect cognitive function through their roles in neurotransmitter synthesis and modulation, axon and myelin sheath integrity and homocysteine metabolism ${ }^{(29)}$. Other effects of the B vitamins may result from deficiencyrelated anaemia, general weakness and poor growth. Dutch infants (aged 4-18 months) on macrobiotic diets from birth had slower gross motor, speech and language development compared with control group infants ${ }^{(30)}$. Dutch youth who followed macrobiotic diets up to 6 years of age had a tendency to perform poorly in cognitive tests in their pre-adolescence and adolescence years $^{(31)}$. Guatemalan school-aged children with vitamin $\mathrm{B}_{12}$ deficiency had slower reaction time on neuropsychological tests of perception, memory and reasoning and more attention problems among others ${ }^{(32)}$.

In addition, most studies on nutrition and cognition have often used dietary nutrient supplements, with information on the effect of diet-based micronutrients on cognitive function relatively sparse in the literature. Recent results from the Child Nutrition Project (CNP), a randomised controlled feeding intervention trial carried out among Kenyan primary school children, reported significantly different rates of increases in cognitive test scores among children assigned to different feeding regimens: meat, milk, vegetarian and control groups ${ }^{(33)}$. Statistically significant differences were noted in rates of test score increase between treatment groups for the Raven's Coloured Progressive Matrices (RCPM) (Psychological Corporation, New York, NY, USA) ${ }^{(34)}$ and arithmetic tests $^{(33)}$. Previous analyses, however, did not report on the relationship between specific dietary nutrients and cognitive function. To provide further understanding of the possible role of specific nutrients on cognitive function, the present analysis was carried out to evaluate the relationship between specific dietary micronutrients and gains in cognitive test scores among primary school children in rural Kenya. Particular attention was paid to those nutrients known to be associated with cognitive function and behaviour, specifically $\mathrm{Fe}, \mathrm{Zn}$ and vitamins $\mathrm{B}_{12}, \mathrm{~B}_{6}$, riboflavin and folic acid ${ }^{(4,10,29,32,35)}$. The CNP utilised a variety of cognitive tests to capture different dimensions of cognitive function: the RCPM to assess higher level of thinking and problem solving, the verbal meaning test to measure expressive language abilities and verbal skills obtained over time, the arithmetic test to tap accumulated oral numeric skills and numeric reasoning obtained over time, and the digit span (DS) test to assess concentration, attention and immediate memory ${ }^{(33,36,37)}$. These tests are used internationally as measures successfully tapping these cognitive abilities in children, and have been used previously in a sample of Kenyan school-age children to measure these specified constructs ${ }^{(36,38)}$. Based on previous human studies and animal trials that have shown improved problem solving, concentration and intelligence among Fe-treated school-age children, a link between dietary $\mathrm{Zn}$ and hippocampus function and short-term memory among juvenile rats and observed memory and attention problems among vitamin $\mathrm{B}_{12}$-deficient school children, we hypothesise that there will be a positive relationship between (i) available Fe and RCPM, (ii) available $\mathrm{Zn}$ and DS tests and (iii) B vitamins and DS tests. Finally, because the arithmetic and the verbal meaning tests measure accumulated skills and knowledge, we hypothesise that there will be a positive association between all nutrients of interest and arithmetic and verbal meaning tests.

\section{Subjects, methods and data collection}

This analysis utilised data collected from the CNP, a randomised controlled feeding intervention study carried out in Kyeni South Division of Embu District in Eastern Province, Kenya from 1998 to $2000^{(39)}$. The study area is rural, and subsistence farming is the primary occupation. All children ( $n$ 554) enrolled in grade 1 (median age 7.4 years) from twelve selected primary schools participated in the study. The schools were randomised to one of four feeding groups: control (no food supplement provided); vegetarian supplement (a feeding based on a traditional local dish (githeri) of maize, beans and vegetables); milk supplement (githeri plus a glass of whole cows' milk $(200 \mathrm{ml})$ ); meat supplement (githeri cooked with $60 \mathrm{~g}$ minced beef). The intervention period was 24 months, starting in August 1998 and ending in July 2000. Schools were in session for 3-month terms, with a 1-month holiday between each term with no feeding. Snacks were prepared every night at a central kitchen, based on pre-tested recipes. Prepared feedings were weighed into individual containers labelled with each child's study numbers and were provided on all school days during the six school terms. The school snacks were approximately isoenergetic and contained an estimated energy content of $1046 \mathrm{~kJ}$ (about $250 \mathrm{kcal}$ ) per serving during the first school term of the intervention (September to November 1998). Then the three snacks were then increased to $1339 \mathrm{~kJ}$ (about $320 \mathrm{kcal}$ ) per serving, by increasing the portion size of the vegetarian supplement (to $230 \mathrm{~g} / \mathrm{child}$ ), the milk content of the milk supplement (to $250 \mathrm{ml}$ ) and the beef content of the meat supplement (to $85 \mathrm{~g}$ ). School snacks were analysed every 3 months to ensure prescribed energy content; micronutrient content was analysed initially and twice yearly thereafter. Project-trained feeding assistants served the supplements to the children in their classrooms and collected information on attendance and collected and measured the snack leftovers. All project enumerators and testers were not blinded from the feeding group assignments but were blinded to the study hypotheses. Supplement consumption levels were high, with supplements completely eaten in over $99 \%$ of the child-feeding sessions ${ }^{(40)}$. A detailed description of the study area and design have been published elsewhere ${ }^{(39)}$.

Human subjects approval was obtained for the research study from the University of California, Los Angeles, the University of Nairobi, School of Medicine, Kenya, and the Office of the President, Government of Kenya. All local and district authorities were supportive and helped facilitate implementation of the study. The community was informed in detail about the aim and procedures of the intervention. Informed verbal consent by parents of study children was obtained before the study.

\section{Cognitive function assessments}

The cognitive battery included four tests: the $\mathrm{RCPM}^{(34)}$, a verbal meaning test, an arithmetic test and digit span (DS)-forward and DS-backward tests. Six local testers 
administered the tests in the Kiembu language. Three of the testers had carried out the cognitive testing during previous work in $\mathrm{Embu}^{(38)}$, and all six received extensive training for the present study. Testing was carried out in an empty classroom at each school in the afternoons. No snacks were provided immediately before, during, or after testing. Testing sessions were $30 \mathrm{~min}$ in duration. Occasionally, testing was carried out on Saturdays so that all study children could be tested within the 3-month school term. Across terms, children were tested in approximately the same order so that time elapsing between testing sessions was equivalent for all children.

These tests were chosen because they had been used extensively in previous research in the study area ${ }^{(38)}$ and because of their ability to capture multiple cognitive constructs that have been shown to be associated with micronutrient status. The RCPM was used to assess problem-solving abilities and requires observation and understanding of abstract patterns and sequences ${ }^{(33,36)}$. Each child was presented with a matrix-like arrangement of symbols and asked to select the correct symbol to complete the pattern. No time limit was set to solve each problem. A total of thirty-six items were administered to each child. The verbal meaning test is similar to the Peabody picture vocabulary test but with pictures ${ }^{(33)}$, and tests for expressive language abilities and verbal skills obtained over time. The test was designed in East Africa and has been previously used in Kenya, Uganda and Tanzania $^{(36)}$. The child was presented with four pictures and asked to point to the one named by the tester. A total of thirty-six items were administered to children, with simpler items requiring recognition of simple nouns, whereas the most advanced items were more abstract concepts. No time limit was set to identify each picture. The pictures and items used in the verbal meaning and arithmetic tests were modified to be more relevant to the Embu context and have been extensively used in a previous study in $\mathrm{Embu}^{(38)}$. The arithmetic test was adapted from the Weschler Intelligence Scales for Children - Revised (Psychological Corporation, New York, NY, USA) ${ }^{(41)}$ and was used to assesses basic knowledge of arithmetic $^{(33)}$. The child was asked to add and subtract simple numbers and then proceed to more difficult items involving division, multiplication and decimals. The test consisted of nineteen orally presented arithmetic word problems and a time limit of $30 \mathrm{~s}$ to reply verbally with the answer to each problem. The DS tests for short-term memory and concentration, and measures the child's ability to remember and repeat aloud a sequence of numbers. The test consisted of fourteen items for the forward and backward recall. The tester read increasingly longer strings of numbers, which the child was asked to recall and repeat in forward order for the DS-forward test and in backward order for the DS-backward test. Though both forward and backward digit recall require acute concentration to perform, each has been noted to also require different mental processes; forward recall taps basic short-term auditory memory, while backward recall invokes more complex processes that require mental transformations. Thus, DS scores were analysed in two different ways: separately and together as DS-total scores ${ }^{(37)}$.

All cognitive tests exhibited stability across testing rounds. Correlations within children were all statistically significant $(P<0.0001)$ and ranged from 0.20 to 0.40 across rounds for the RCPM, 0.35 to 0.61 for the verbal meaning test, 0.41 to
0.61 for the arithmetic test, 0.46 to 0.64 for the DS-forward, 0.30 to 0.43 for the DS-backward and 0.44 to 0.59 for the DS-total. Construct validity was assessed by comparing correlations between the cognitive test scores and school examination scores across different testing rounds. Across the different testing rounds, correlations ranged from 0.20 to 0.23 between the RCPM and the mean examination scores, 0.23 to 0.27 between the verbal meaning and Kiembu language examination scores, 0.33 to 0.46 between the arithmetic and mathematics examination scores and 0.23 to 0.36 between the DS test scores and the mean examination scores. All correlations were statistically significant. To ensure inter-rater reliability across the study period, a sub-sample of the children $(16 \%)$ was tested simultaneously by two enumerators during each round of testing and inter-rater score correlations ranged from 0.98 to $1.00^{(33)}$. On a weekly basis, all six testers rotated schools to control for any bias, and rotated testing partners to ensure reliability across all testers.

\section{Food intake}

Dietary information for each child came from two sources: a $24 \mathrm{~h}$ recall interview with the child's mother or caretaker and a CNP snack consumption record obtained at school. Twelve women with previous experience in dietary data collection methods ${ }^{(38)}$ were retrained to conduct $24 \mathrm{~h}$ recall interviews at home. Information on daily non-CNP snack intake for each study child was obtained, with the mothers being the main respondents. The enumerators did not work over the weekend, and so the dietary data collected reflected what was consumed on any $1 \mathrm{~d}$ from Sunday through to Thursday. Procedures followed in determining nutrient intake have been previously described ${ }^{(42)}$. In summary, mothers were asked to estimate amounts of foods consumed by the child, mixed dishes prepared in the home and ingredients used in mixed dishes prepared in the home. Common portion measures and food models were used and later converted to $g$ weights using a database developed for this purpose. Mothers were also probed about foods consumed or brought into the home and asked to describe the primary ingredients for any out-of-home mixed dishes. Standard recipes were used to help determine the nutrient intake from these mixed dishes. The standard recipes were based on dietary information that had been collected in a previous study in the same study area ${ }^{(38)}$ and were updated to reflect any recipe-content changes that had taken place over the years. Enumerators were rotated to different areas on a weekly basis to control for any bias. Twenty-four-hour recall interviews were conducted for a total of $19 \mathrm{~d}$ (at least $1 \mathrm{~d}$ per month) over a 2-year period. CNP snacks were served in the classrooms every school day by project-trained feeding assistants. The project feeding assistants recorded absences, types and amount of snacks served and leftovers for each child. The project nutritionist (C. A. G.) conducted ongoing training of the enumerators and assistants and, together with a field supervisor, regularly supervised data collection in the field to ensure data quality.

If a child attending the non-control school consumed a CNP snack on the recall day, the amount of snack served was automatically added to the $24 \mathrm{~h}$ recall foods, reported by the child's mother, to provide a more complete and accurate representation of the day's intake. Snack leftovers, if any, were 
subtracted from the standard portion size of the snack supplement for each child. Nutrient intakes were calculated for each child using an international food composition table adapted for use in the present study (University of California, Berkeley, CA, USA) ${ }^{(43)}$ that contains complete nutrient values for the foods commonly consumed in rural Kenya. The nutrient contents of less common foods were estimated from similar foods. Fe and $\mathrm{Zn}$ availability was calculated using the approach described by Murphy et al. ${ }^{(44)}$. Energy intake per kg body weight (ENGKG) was also calculated.

\section{Socio-economic status of the family}

Information on household socio-economic status (SES) was collected through interviews with the lead female or male in each household. The SES questionnaire was based on the SES ranking criteria identified by the area community leaders ${ }^{(39)}$, which included possessions, economic status and social status. Specific criteria involved land ownership and usage, income and expenditures, household possessions, house type, highest grade of formal education attained by parents and literacy, involvement of parents in leadership and community positions and 'modernity' indices, such as use of bank, telephone and/or post office, listening to radio and reading of newspaper. Variables were weighted, and a composite SES score was developed by adding up the points, whereby a higher score represents a higher level of SES.

\section{Morbidity recall}

Morbidity recall interviews were conducted monthly in year 1 and bimonthly in year 2. A trained enumerator visited the household and carried out a semi-structured interview with the caregiver, usually the mother, on any illness or symptoms that the child experienced on the day of the interview and during the previous 1 week, and the number of days the illness or symptom lasted. A physical inspection was carried out on a sick child if at home. Procedures followed in conducting morbidity recall interviews and quality-control measures have been previously described ${ }^{(39)}$. A score of 1 was assigned to each illness or condition episode. The possible minimum and maximum scores were 0 and 28 per recall interview visit. An average morbidity score was then calculated over fifteen recalls over a 2 -year period.

\section{Weight and height}

Weight was measured, monthly in the first year and bimonthly thereafter, to the nearest $0.1 \mathrm{~kg}$ on an electronic digital scale (Seca, Columbia, MD, USA), with shoes and as many clothes as possible removed. The estimated weight of the clothes was deducted from the weight of the children. Height was measured, every 4 months in the first year and every 8 months thereafter, with the children shoeless, to the nearest $0 \cdot 1 \mathrm{~cm}$ using a locally manufactured wooden board fitted with a steel measuring tape, a fixed foot plate and a movable headboard. Measurements were generally conducted at school; however, when a child was absent or when the school was closed, measurements were made at the child's home. Procedures followed in determining children's weight and height and ensuring quality control have been previously described $^{(45)}$. Two enumerators obtained all measurements independently. Their measurements were averaged and the mean was used as the actual value. Measurements were repeated if the difference of measurements exceeded preset limits $(0.1 \mathrm{~kg}$ for weight and $0.5 \mathrm{~cm}$ for height) and all four values were averaged and the mean used as the reported value. Weight and height measures were transformed to weight-for-age $z$-scores, weight-for-height $z$-scores and height-for-age $z$-scores (HAZ scores) via the EpiInfo2005 program (version 3.3; Centers for Disease Control and Prevention (CDC), Atlanta, GA, USA), which uses the CDC/WHO 1978 reference curves for age, sex, height and weight.

\section{Data analysis}

All forms were checked daily by the supervisors in the field to allow immediate revisits for gross errors or missing data. The data were then entered and checked for errors against the forms and range-checked by computer. Forms with missing information and/or correctable errors were sent back to the field for confirmation and completion. SAS version 8.2 (SAS Institute, Cary, NC, USA) was used for data analysis. Fifteen children switched treatment groups after the intervention had started, and their data were included in the analysis up to the point of the switch. Raw, non-standardised cognitive test scores were utilised in the data analysis. An $\alpha$ level of 0.05 was used to indicate statistical significance.

Longitudinal data models were fit with the SAS mixed procedure (SAS version 8; SAS Institute, Cary, NC, USA). Restricted maximum likelihood estimation was used for longitudinal analysis ${ }^{(46)}$. It was assumed that each child followed a subject-specific trajectory over time, modelled as a random intercept and slope. Models were fit using nutrient intake variables as predictors and cognitive test score variables as responses. Only covariates that were significantly associated with any cognitive test score $(P<0.05)$ were included in the final analysis. Despite there being a positive association between HAZ and cognitive test scores, there were very strong positive correlations between HAZ and SES scores, and so a decision was made to exclude HAZ scores from the final regression to maintain model stability. Sex, age at start of feeding intervention, SES and morbidity were included in the analysis as covariates. Models were adjusted for treatment by including school and school $\times$ time interactions. Nutrient intake was adjusted for energy intake by weight with ENGKG included in the model. Interactions between time and each covariate were included to capture change in cognitive test score slope associated with each respective covariate and nutrient. Interactions between sex and nutrient and between sex, nutrient and time were included to test for any sex differences. The coefficient of the nutrient $\times$ time interaction indicates the effect of nutrient on gains of cognitive test scores over time and was the key parameter of interest. A positive coefficient of the nutrient $\times$ time interaction indicates that higher levels of nutrient intake lead to greater gains in cognitive test scores over time, while a negative coefficient of the nutrient $\times$ time interaction indicates that higher levels of nutrient intake lead to lower gains in cognitive test scores over time. Differences in test score changes over 2 years between children at the 90 th and 10th percentile of 
Table 1. Sociodemography, morbidity and baseline anthropometry and cognitive test scores (Mean values and standard deviations)

\begin{tabular}{|c|c|c|c|c|c|c|}
\hline & \multicolumn{2}{|c|}{ All } & \multicolumn{2}{|c|}{ Boys } & \multicolumn{2}{|c|}{ Girls } \\
\hline & Mean & SD & Mean & SD & Mean & SD \\
\hline Age (years) $\dagger$ & $7 \cdot 60$ & 1.30 & $7 \cdot 80$ & 1.50 & $7 \cdot 40$ & $1 \cdot 19$ \\
\hline SES (score) $\ddagger$ & $75 \cdot 60$ & 23.02 & 73.90 & 23.40 & $77 \cdot 50$ & $22 \cdot 5$ \\
\hline Morbidity (score) $\ddagger$ & 1.26 & 0.69 & 1.24 & 0.69 & $1 \cdot 28$ & 0.68 \\
\hline \multicolumn{7}{|l|}{ Baseline anthropometry } \\
\hline Underweight (WAZ score <-2) $(\%) \S$ & \multicolumn{2}{|c|}{17} & \multicolumn{2}{|c|}{$20^{*}$} & \multicolumn{2}{|c|}{13} \\
\hline Stunted $(\mathrm{HAZ}$ score $<-2)(\%) \S$ & \multicolumn{2}{|c|}{29} & \multicolumn{2}{|c|}{$34^{*}$} & \multicolumn{2}{|c|}{24} \\
\hline Wasted $(\mathrm{WHZ}$ score $<-2)(\%) \|$ & \multicolumn{2}{|c|}{0.63} & \multicolumn{2}{|c|}{0.39} & \multicolumn{2}{|c|}{0.90} \\
\hline \multicolumn{7}{|l|}{ Baseline cognitive scores $\ddagger$} \\
\hline RCPM (score) & $17 \cdot 37$ & 2.45 & 17.53 & 2.40 & $17 \cdot 20$ & 2.48 \\
\hline Verbal meaning (score) & $27 \cdot 10$ & $4 \cdot 81$ & $27 \cdot 60^{*}$ & 4.75 & $26 \cdot 60$ & 4.82 \\
\hline Arithmetic (score) & $7 \cdot 07$ & 1.63 & $7 \cdot 19$ & 1.55 & 6.93 & 1.71 \\
\hline DS-forward test (score) & 2.79 & $1 \cdot 12$ & 2.78 & 1.06 & $2 \cdot 80$ & $1 \cdot 19$ \\
\hline DS-backward test (score) & $2 \cdot 26$ & 1.07 & $2 \cdot 21$ & 1.00 & 2.32 & 1.14 \\
\hline DS-total test (score) & 5.05 & 1.78 & $4.99^{\star}$ & 1.64 & $5 \cdot 11$ & 1.92 \\
\hline
\end{tabular}

SES, socio-economic status; WAZ score, weight-for-age z-score; HAZ score, height-for-age z-score; WHZ score, weight-for-height $z$-score; RCPM, Raven's Coloured Progressive Matrices; DS, digit span.

${ }^{*}$ Mean value or proportion was significantly different from that of the girls $(P<0.05)$

†For age, $n 529$ for all children, $n 276$ for boys, $n 253$ for girls.

¥For SES, morbidity and cognitive test scores, $n 520$ for all children, $n 270$ for boys, $n 250$ for girls.

$\S$ For percentage underweight and stunted, $n 491$ for all children, $n 259$ for boys, $n 232$ for girls.

|| For percentage wasted, $n 476$ for all children, $n 254$ for boys, $n 222$ for girls.

nutrient level intake were calculated for those nutrients that had shown statistically significant effects on the test score changes using the formula: slope estimate (nutrient $\times$ time $) \times 24 \times(90$ th percentile daily nutrient level -10 th percentile daily nutrient level). Further analysis to assess between-sex differences, by including a nutrient $\times \operatorname{sex} \times$ time interaction, did not yield any statistically significant results.

\section{Results}

Five hundred and twenty-nine school children had sets of cognitive test and dietary intake measures. Overall $90 \%$ of children had cognitive test scores from all testing rounds, and $97 \%$ of the children had scores from at least four testing rounds. Boys made up $52.8 \%$ of the sample and were significantly older than the girls (Table 1). The SES composite score ranged from 19 to 144 points, while the morbidity score ranged from 0 to $3 \cdot 64$. No significant differences were noted in SES and morbidity scores between boys and girls. Significant between-sex differences were noted in verbal meaning and DS-total test scores at baseline, with boys having higher verbal meaning test scores compared with girls and girls having higher DS-total test scores compared with boys (Table 1). Prevalence of underweight and stunting was significantly higher among the boys at baseline compared with the girls.

No between-sex differences were noted in ENGKG at post-baseline. However, boys had significantly higher intakes of total energy, protein, available $\mathrm{Fe}$, available $\mathrm{Zn}$, folate, vitamin $\mathrm{B}_{6}$ and riboflavin compared with girls (Table 2).

The results of the longitudinal regression models are shown in Table 3. As mentioned, interactions with the child's sex

Table 2. Daily nutrient intake among Kenyan school children at post-baseline† (Mean values and standard deviations)

\begin{tabular}{|c|c|c|c|c|c|c|}
\hline \multirow[b]{2}{*}{ Nutrient } & \multicolumn{2}{|c|}{ All } & \multicolumn{2}{|c|}{ Boys } & \multicolumn{2}{|c|}{ Girls } \\
\hline & Mean & SD & Mean & SD & Mean & SD \\
\hline Energy (kJ) & 7490 & 1170 & $7766^{\star \star \star}$ & 1188 & 7209 & 1079 \\
\hline Energy (kcal) & 1792 & 280 & 1857 & 284 & 1724 & 258 \\
\hline ENGKG (kJ/kg) & 342 & 62 & 347 & 64 & 337 & 61 \\
\hline ENGKG (kcal/kg) & 81.83 & 14.93 & 83.00 & $15 \cdot 30$ & $80 \cdot 50$ & 14.50 \\
\hline Protein $(\mathrm{g})$ & 53.95 & $10 \cdot 26$ & $56 \cdot 00^{\star \star \star \star}$ & $10 \cdot 50$ & 51.60 & 9.50 \\
\hline Available $\mathrm{Fe}(\mathrm{mg})$ & 1.48 & 0.36 & $1.53^{\star \star}$ & 0.40 & 1.40 & 0.30 \\
\hline Available $\mathrm{Zn}$ (mg) & 1.00 & 0.20 & $1.03^{\star \star \star}$ & 0.20 & 0.97 & 0.20 \\
\hline Vitamin $B_{12}(\mu \mathrm{g})$ & 0.64 & 0.38 & 0.65 & 0.40 & 0.62 & 0.40 \\
\hline Folate $(\mu \mathrm{g})$ & 514 & 119 & $541^{\star \star \star \star}$ & 121 & 484 & 110 \\
\hline Vitamin $B_{6}(\mathrm{mg})$ & $2 \cdot 40$ & 0.54 & $2 \cdot 50^{\star \star \star \star}$ & 0.60 & $2 \cdot 30$ & 0.50 \\
\hline Riboflavin (mg) & 1.13 & 0.19 & $1 \cdot 17^{\star \star \star \star}$ & 0.20 & 1.08 & 0.20 \\
\hline
\end{tabular}

ENGKG, energy intake per kg body weight.

Mean value was significantly different from that of the girls: ${ }^{\star *} P<0.01,{ }^{\star \star \star *} P<0.001,{ }^{\star \star \star \star *} P<0.0001$.

†For all nutrients except ENGKG, $n 529$ for all children, $n 276$ for boys, $n 253$ for girls. For ENGKG, $n 504$ for all children, $n 265$ for boys, $n 240$ for girls. 
were tested and then removed from the model because they were not statistically significant. Differences in RCPM test score gains were positively predicted by daily available $\mathrm{Fe}$ intake. For every $1 \mathrm{mg}$ difference in available Fe intake, the difference in RCPM score gains was 0.066 points for every month spent in the study. Differences in DS-forward test score gains were positively predicted by daily vitamin $B_{12}$ and riboflavin intakes. Differences in DS-total test score gains were positively predicted by daily available $\mathrm{Zn}$ intakes.

Differences in test score gains between those children with high daily nutrient intake levels (90th percentile) and those with low intake levels (10th percentile) were calculated for those nutrients that had shown statistically significant effects on the test score changes, to illustrate the effects of specific nutrient intake on cognitive test score gains over 24 months (Fig. 1). Test score gains for those with high nutrient intake have steeper slopes and consequently higher test scores over the 24-month period. A child with a daily high intake of available Fe gained 1.404 more points in the RCPM test. A child with a daily high intake of vitamin $B_{12}$ gained 0.24 more points in the DS-forward test than one with low intake level, while a child with a daily high intake of riboflavin gained 0.45 more points in the same test than one with low intake level. A child with a daily high intake of available $\mathrm{Zn}$ gained 0.73 more points in the DS-total test. When compared with the baseline standard deviation, these differences represent a $50 \%$ upward shift in the entire population for the effect of available Fe on RCPM, a $20 \%$ upward shift for the effect of vitamin $\mathrm{B}_{12}$ on DS-forward, a $40 \%$ upward shift for the effect of riboflavin on DS-forward and a $40 \%$ shift for the effect of available Zn on DS-total.

\section{Discussion}

The CNP study provided an opportunity to test the relationship between specific dietary micronutrients and cognitive test score changes over time. Mean ENGKG seemed adequate when compared with energy requirements for 7-8-year-olds engaged in moderate physical activity $(280 \mathrm{~kJ} / \mathrm{kg}(67 \mathrm{kcal} / \mathrm{kg})$ for girls and $297 \mathrm{~kJ} / \mathrm{kg}(71 \mathrm{kcal} / \mathrm{kg} \text { ) for boys })^{(47)}$. Boys had significantly higher intakes for all micronutrients of interest, except vitamin $\mathrm{B}_{12}$, at post-baseline. These children, however, are underweight and stunted ${ }^{(45)}$, and they require higher energy and nutrient intake levels to allow catch-up growth. Previous studies and analyses have shown that the usual diets in this area are predominantly plant-based ${ }^{(38,42)}$, with only $4 \%$ of energy coming from animal source foods (ASF) ${ }^{(38,42)}$. The school children's available $\mathrm{Fe}$ and $\mathrm{Zn}$ intake values are below the estimated average requirements for this group of children ${ }^{(48)}$. The higher verbal meaning test scores noted among boys at baseline were unexpected and are inconsistent with findings from other studies $^{(49)}$. Although not tested in this particular analysis, we may speculate that the unexpected results could be due to age and social interaction differences between boys and girls.

Positive changes in RCPM test score gains were positively predicted by daily available $\mathrm{Fe}$ intake. Animal trials have demonstrated that brain $\mathrm{Fe}$ is sensitive to dietary $\mathrm{Fe}^{(10,12)}$, and previous studies in humans have reported positive relationships between $\mathrm{Fe}$ treatment and improved concentration and intelligence quotient ${ }^{(5,7,8,50,51)}$. The present analysis reinforces the importance of dietary Fe in improving 

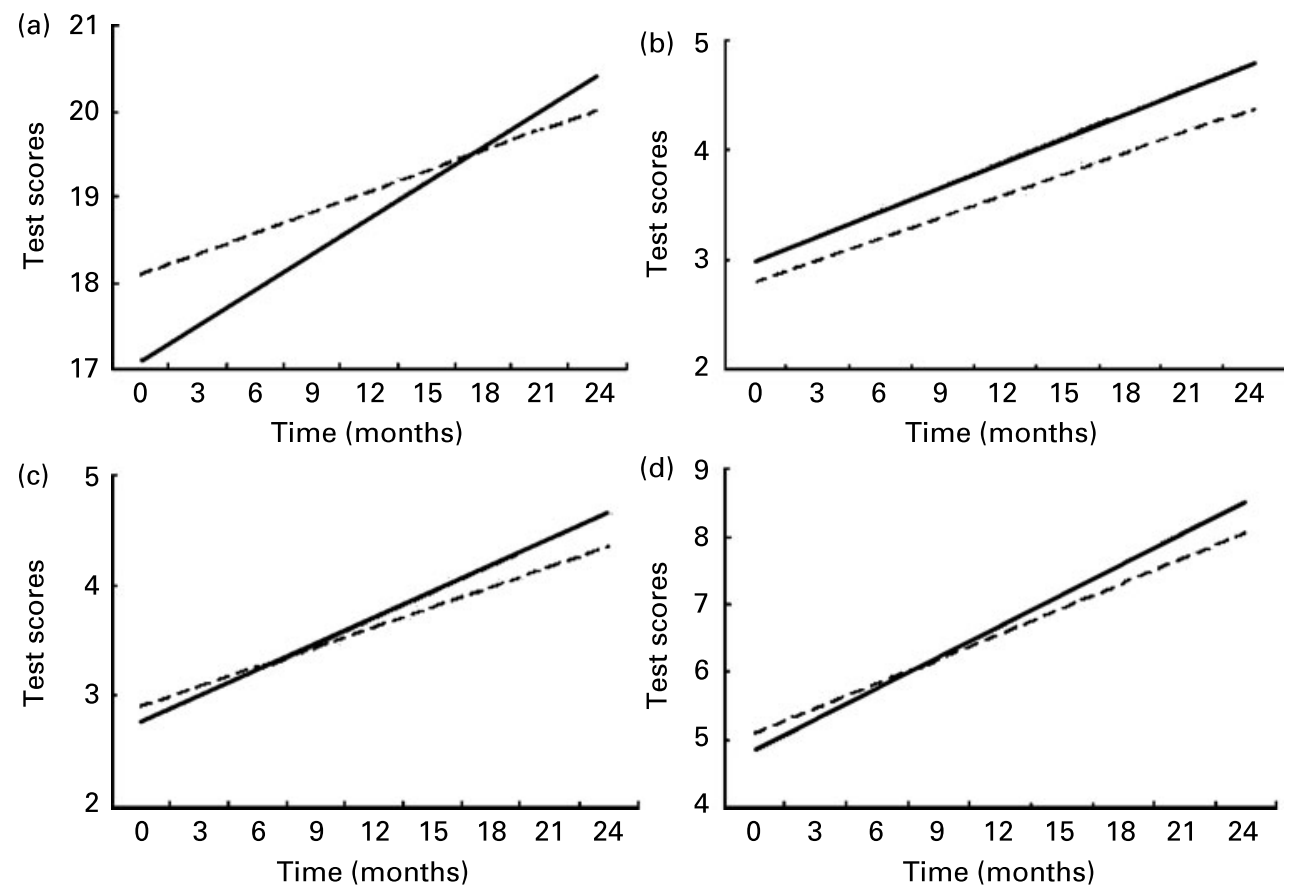

Fig. 1. Comparing test scores between children with low (90th percentile; - - - - -) and high (10th percentile; - - ) daily nutrient intake levels: (a) available Fe and Raven's Coloured Progressive Matrices test score; (b) vitamin $\mathrm{B}_{12}$ and digit span-forward test score; (c) riboflavin and digit span-forward test score; (d) available $\mathrm{Zn}$ and digit span-total test score. Covariates were: sex, age at start of feeding intervention, socio-economic status, morbidity, school and energy intake per kg body weight.

cognitive function in development. Available $\mathrm{Zn}$ intake significantly predicted gains in DS-total test scores over time. Children with higher available $\mathrm{Zn}$ intake produced significantly higher test score gains compared with those with lower intakes. Just as with available $\mathrm{Fe}$, available $\mathrm{Zn}$ is found predominantly in ASF. Despite inconsistent results on $\mathrm{Zn}$ and cognitive function among humans, animal trials have been consistent in reporting worsened short-term memory, spontaneous motor activity, visual attention and learning in Zn-deficient animals ${ }^{(26,28,52)}$. In the present study, children with higher intake of $\mathrm{B}$ vitamins ( $\mathrm{B}_{12}$ and riboflavin) experienced significantly higher DS-forward test score gains compared with those with lower intakes. Vitamin $\mathrm{B}_{12}$ is solely found in ASF, while riboflavin is predominantly found in meat and dairy products. $B$ vitamins may affect cognitive function and development through their roles in neurotransmitter synthesis and modulation, axon and myelin sheath integrity and homocysteine metabolism ${ }^{(29)}$ and possibly reduced exploration due to anaemia and poor growth. Memory, reasoning and attention problems have been reported among vitamin $\mathrm{B}_{12}$-deficient school children ${ }^{(32)}$. There was no evidence of significant positive associations between any of the nutrients and verbal meaning or arithmetic tests.

The previous analyses within the CNP that looked at change in cognitive test scores on the basis of the feeding group assignment showed that school children who received the meat supplement had significantly higher gains in the RCPM scores compared with the milk, vegetarian and control groups, and that arithmetic test score gains for the vegetarian group were significantly higher than those for the milk and control groups ${ }^{(33)}$. The present findings are consistent with previous results. However, the present analyses did not show any significant association between any of the dietary nutrients tested and arithmetic test score gains, possibly indicating the role of other dietary components not captured by the nutrients tested. Although the previous study on this sample did not report on the DS tests, the present study results indicate significant nutrient effects on DS-forward and DS-total scores over time, suggesting some association of these nutrients with short-term memory and concentration functions in children.

The strengths of the present study include the use of multiple well-tested tools and analyses controlling for a number of factors associated with cognitive function. It has been noted that common cognitive constructs are best represented by functions that are mediated by several dissociable neural pathways $^{(53)}$, and a battery of cognitive tests was used to capture different aspects of cognitive function. The cognitive tests enlisted in the present study have previously been used in the study area and are well used internationally. Previous assessment of Embu school children's cognitive performance indicated that the RCPM, verbal meaning and DS tests exhibited stability across testing periods and also captured some of the skills acquired and required in the local schools ${ }^{(36,54,55)}$. An assessment of performance on the RCPM among Kenyan school children, ages 6 to 11 years, indicated high levels of internal consistency and reliability, thus lending more support to the appropriateness of using the RCPM as a measure of abstract problem-solving ability among Kenyan school children ${ }^{(55)}$. Dietary data were collected multiple times over a period of 2 years, providing close to usual intake estimates among the school children. The analysis in the present study also adjusted for other factors that have been shown to influence cognitive outcome and may thus confound the relationship between the nutrients of interest and cognitive 
outcome. Controlling for school effect allowed us to test for nutrient and other effects that are above school and treatment effects on the cognitive test scores.

The use of recall dietary intake data is a limitation of the study. Although weighing of food intake provides a better estimate of dietary intake, we have found that the use of recall dietary information carefully done provides a good estimate of dietary intake. The appropriateness of the $24 \mathrm{~h}$ recall method in Kenya has been previously assessed, with results indicating no statistically significant differences between weighed foods and $24 \mathrm{~h}$ recall estimates among preschool children and the elderly ${ }^{(56)}$. Similar analysis using the CNP data indicated high levels of agreement between weighed records and $24 \mathrm{~h}$ recall estimates (CA Gewa, SP Murphy and CG Neumann, unpublished results). Weighing of food is relatively expensive for large studies. It may also result in study participants altering their dietary behaviour, especially if enumerators are required to observe, weigh and record the study participants' intake. In an effort to maintain model stability, the study does not control for height measure, which has been shown to be associated with cognitive function. The analysis also does not control for Fe-deficiency anaemia.

ASF, especially meat, provide the highest sources of micronutrients assessed in the present study. However, most families in less-developed regions still face many challenges in providing ASF, both milk and meat ${ }^{(57,58)}$. Trials of the safety, nutrient quality, acceptability and production of smaller animals and insects are few and could offer some solutions in different cultures. Other strategies include food fortification and home-based bioavailability-enhancing methods, such as germination, fermentation and phytate reduction through presoaking ${ }^{(59-61)}$. These results demonstrate the importance of an improved intake of dietary micronutrients contained in ASF, specifically available Fe, available $\mathrm{Zn}$, vitamin $\mathrm{B}_{12}$ and riboflavin, on cognitive function among school-aged children. Investment in school children through nutrition improvement is an investment in their academic performance.

\section{Acknowledgements}

Preliminary results of these analyses were presented at the 2008 Federation of American Societies for Experimental Biology (FASEB) conference, San Diego, CA, USA. The poster title was 'Dietary micronutrients are associated with higher cognitive function gains among primary school children in rural Kenya'.

The present study was supported by the Global Livestock Collaborative Research Support Program, University of California at Davis, through the US Agency for International Development (grant number PCE-G-00-98-00 036-00). We would also like to thank the CNP cognitive testing field supervisor, Ms Minnie Kamore and all participants and workers of the CNP, and Natalie Drorbaugh and Mari Davies for their feedback and editorial assistance. C. A. G. was the field nutritionist for CNP, oversaw the dietary data collection and management, was responsible for the statistical analysis and wrote the manuscript. Dan Guthrie was responsible for the overall design of the original CNP study and R. E. W. provided guidance in the statistical analysis used in this manuscript. N. O. B. was the Kenyan principal investigator for CNP and was responsible for the overall research activities in the field.
M. S. was a co-principal investigator for CNP and was responsible for the cognitive assessment used. S. W. was a coprincipal investigator for $\mathrm{CNP}$ and was responsible for the cognitive assessment. S. P. M. was a co-principal investigator for CNP and was responsible for the dietary data methodology used. G. H. helped guide the analysis and writing of the manuscript. C. G. N. was the principal investigator for CNP, was responsible for the study design, oversaw overall research activities and helped guide the statistical analysis and writing of the manuscript. All authors read and contributed to the finalisation of the manuscript. The sponsors of the study and the authors had no conflicts of interest.

\section{References}

1. Lozoff B (1989) Nutrition and behavior. Am Psychol 44, 231-236.

2. Grantham-McGregor SM \& Ani CC (1999) The role of micronutrients in psychomotor and cognitive development. $\mathrm{Br}$ Med Bull 55, 511-527.

3. Grantham-McGregor SM \& Ani C (2001) A review of studies on the effect of iron deficiency on cognitive development in children. $J$ Nutr 131, 649S-668S.

4. Bryan J, Osendarp S, Hughes D, Cavaresi E, Baghurst K \& van Klinken J-W (2004) Nutrients for cognitive development in school-aged children. Nutr Rev 62, 295-306.

5. Seshadri S \& Gopaldas T (1989) Impact of iron supplementation on cognitive functions in preschool and school-aged children: the Indian experience. Am J Clin Nutr 50, 675-686.

6. Soemantri AG (1989) Preliminary findings on iron supplementation and learning achievement of rural Indonesian children. Am J Clin Nutr 50, 698-702.

7. Pollitt E, Hathirat P, Kotchabhakdi NJ, Missell L \& Valyasevi A (1989) Iron deficiency and educational achievement in Thailand. Am J Clin Nutr 50, 687-697.

8. Bruner AB, Joffe A, Duggan AK, Casella JF \& Brandt J (1996) Randomised study of cognitive effects of iron supplementation in non-anaemic iron-deficient adolescent girls. Lancet 348, 992-996

9. Nelson CA, Erikson K, Pinero DJ \& Beard JL (1997) In vivo dopamine metabolism is altered in iron-deficient anemic rats. J Nutr 127, 2282-2288.

10. Pinero DJ \& Connor JR (2005) Iron and brain function. In Nutritional Neuroscience, pp. 235-258 [HR Lieberman, R Kanarek and C Prasad, editors]. Boca Raton, FL: Taylor \& Francis.

11. Connor JR \& Menzies SL (1996) Relationship of iron to oligodendrocytes and myelination. Glia 17, 83-93.

12. Pinero DJ, Li N, Connor JR \& Beard JL (2000) Variations in dietary iron alter brain iron metabolism in developing rats. J Nutr 130, 254-263.

13. Beard JL, Erikson KM \& Jones BC (2002) Neurobehavioral analysis of developmental iron deficiency in rats. Behav Brain Res 134, 517-524.

14. Beard JL \& Connor JR (2003) Iron status and neural functioning. Annu Rev Nutr 23, 41-58.

15. Beard J (2007) Recent evidence from human and animal studies regarding iron status and infant development. J Nutr 137, 524S-530S.

16. Eichenbaum H (2004) Hippocampus: cognitive processes and neural representations that underlie declarative memory. Neuron 44, 109-120.

17. Nieoullon A (2002) Dopamine and the regulation of cognition and attention. Prog Neurobiol 67, 53-83.

18. Nieoullon A \& Coquerel A (2003) Dopamine: a key regulator to adapt action, emotion, motivation and cognition. Curr Opin Neurol 16, S3-S9. 
19. Pollitt E (1993) Iron deficiency and cognitive function. Annu Rev Nutr 13, 521-537.

20. Lozoff B (1998) Explanatory mechanisms for poorer development in iron-deficient anemic infants. In Nutrition, Health, and Child Development: Research Advances and Policy Recommendations, pp. 162-178. Washington, DC: Pan American Health Organization (PAHO), The World Bank and Tropical Metabolism Research Unit, University of West Indies.

21. Lozoff B, Klein NK \& Prabucki KM (1986) Iron-deficient anemic infants at play. $J$ Dev Behav Pediatr 7, 152

22. Black MM (2003) The evidence linking zinc deficiency with children's cognitive and motor functioning. $J$ Nutr $\mathbf{1 3 3}$, 1473S-1476S

23. Gibson RS, Vanderkooy PDS, MacDonald AC, Goldman A, Ryan BA \& Berry M (1989) A growth-limiting, mild zincdeficiency syndrome in some Southern Ontario boys with low height percentiles. Am J Clin Nutr 49, 1266-1273.

24. Cavan KR, Gibson RS, Grazioso CF, Isalgue AM, Ruz M \& Solomons NW (1993) Growth and body composition of periurban Guatemalan children in relation to zinc status: a longitudinal zinc intervention trial. Am J Clin Nutr 57, 344-352.

25. Sandstead HH, Pentland JG, Alcock NW, Dayal HH, Chen XC, Li JS, Zhao F \& Yang JJ (1998) Effects of repletion with zinc and other micronutrients on neuropsychologic performance and growth of Chinese children. Am J Clin Nutr 68, 470S-475S

26. Takeda A, Takefuta S, Okada S \& Oku N (2000) Relationship between brain zinc and transient learning impairment of adult rats fed zinc-deficient diet. Brain Res 859, 352-357.

27. Takeda A, Minam A, Takefuta S, Tochigi M \& Oku N (2001) Zinc homoeostasis in the brain of adult rats fed zinc-deficient diet. J Neurosci Res 63, 447-452.

28. Keller KA, Grider A \& Coffield JA (2001) Age dependent influence of dietary zinc restriction on short-term memory in male rats. Physiol Behav 72, 339-348.

29. Huller J (2005) Vitamins and brain function. In Nutritional Neuroscience, pp. 207-233 [H Lieberman, R Kanarek and C Prasad, editors]. Boca Raton, FL: Taylor \& Francis.

30. Dagnelie PC \& Van Staveren WA (1994) Macrobiotic nutrition and child health: results of a population-based, mixed longitudinal cohort study in the Netherlands. Eur J Clin Nutr 59, $1187 \mathrm{~S}-1196 \mathrm{~S}$.

31. Louman MWJ, van Dusseldorp M, van de Vijer FJR, Thomas CMG, Schneede J, Ueland PM, Refsum H \& van Staveren WA (2000) Signs of impaired cognitive function in adolescents with marginal cobalamin status. Am J Clin Nutr 72, 762-769.

32. Black MM (2003) Micronutrient deficiencies and cognitive functioning. J Nutr 133, 3927S-3931S.

33. Whaley SE, Sigman M, Neumann C, Bwibo N, Guthrie D, Weiss RE, Alber S \& Murphy SP (2003) The impact of dietary intervention on the cognitive development of Kenyan school children. J Nutr 133, 3965S-3971S.

34. Raven TC (1960) Raven's Progressive Matrices. New York: Psychological Corporation.

35. Bray TM \& Levy MA (2005) Dietary zinc in brain development, behavior, and neuropathology. In Nutritional Neuroscience, pp. 275-288 [HR Lieberman, R Kanarek and C Prasad, editors]. Boca Raton, FL: Taylor \& Francis.

36. Sigman M, Neumann C, Jansen AA \& Bwibo N (1989) Cognitive abilities of Kenyan children in relation to nutrition, family characteristics and education. Child Dev 60, 1463-1474.

37. Reynolds CR (1997) Forward and backward memory span should not be combined for clinical analysis. Arch Clin Neuropsychol 12, 29-40.

38. Neumann C, Bwibo NO \& Sigman M (1987) Diet Quantity and Quality. Functional Effects on Rural Kenyan Families. Kenya Project Final Report. Phase II - 1989-1992. Human Nutrition
Collaborative Research Support Program. Los Angeles, CA: UCLA School of Public Health.

39. Neumann CG, Bwibo NO, Murphy SP, Sigman M, Whaley S, Allen LH, Guthrie D, Weiss RE \& Demment MW (2003) Animal source foods improve dietary quality, micronutrient status, growth and cognitive function in Kenyan school children: background, study design and baseline findings. $J$ Nutr 133, 3941S-3949S

40. Gewa C, Murphy SP, Bwibo NO \& Neumann CG (2005) Assessment of Snack Acceptance during a School Feeding Intervention in Rural Kenya. Global Livestock CRSP Research Brief 05-03-CNP. Davis, CA: Global Livestock Collaborative Research Support Program.

41. Weschler D (1974) Weschler Intelligence Scale for Children Revised. New York: Psychological Corporation.

42. Murphy SP, Gewa C, Liang L, Grillenberger M, Bwibo NO \& Neumann CG (2003) School snacks containing animal source foods improve dietary quality for children in rural Kenya. $J$ Nutr 133, 3950S-3956S

43. Calloway DH, Murphy SP, Bunch S \& Woerner J (1994) World Food Dietary Assessment System User's Guides. Berkeley, CA: University of California, Berkeley.

44. Murphy SP, Beaton GH \& Calloway DH (1992) Estimated mineral intakes of toddlers: predicted prevalence of inadequacy in village populations in Egypt, Kenya and Mexico. Am J Clin Nutr 56, 565-572.

45. Grillenberger M, Neumann CG, Murphy SP, Bwibo NO, van't Veer P, Hautvast JG \& West CE (2003) Food supplements have a positive impact on weight gain and the addition of animal source foods increases lean body mass of Kenyan schoolchildren. J Nutr 133, 3957S-3964S.

46. Weiss RE (2005) Modeling Longitudinal Data. New York, NY: Springer.

47. Food and Agriculture Organization (2001) Human Energy Requirements. Joint FAO/WHO/UNU Expert Consultation. Food and Nutrition Technical Report Series. Rome: FAO.

48. Institute of Medicine (2006) Dietary Reference Intakes: The Essential Guide to Nutrient Requirements, pp. 38, 531 [Otten JJ, Hellwig JP and Meyers LD, editors]. Washington, DC: The National Academies Press.

49. Halpern DF (2000) Sex Differences in Cognitive Abilities, 3rd ed. Mahwah, NJ: Lawrence Erlbaum Associates.

50. Pollitt E, Soemantri AG, Yunis F \& Scrimshaw NS (1985) Cognitive effects of iron deficiency anemia. Lancet $\mathbf{i}, 158$.

51. Soemantri AG, Pollitt E \& Kim I (1985) Iron deficiency anemia and educational achievement. Am J Clin Nutr 42, 1221-1228.

52. Golub MS, Takeuchi PT, Keen CL, Gershwin ME \& Hendricks AG (1994) Modulation of behavioral performance of prepubertal monkeys by moderate dietary zinc deprivation. Am J Clin Nutr 60, 238-243.

53. Wainwright PE \& Colombo J (2006) Nutrition and the development of cognitive functions: interpretation of behavioral studies in animals and human infants. Am J Clin Nutr 84, 961-970.

54. Daley TC, Whaley SE, Sigman MD \& Espinosa MP (2003) IQ on the rise. The Flynn effect in rural Kenyan children. Psychol Sci 14, 215-219.

55. Costenbader V \& Ngari SM (2001) A Kenya standardization of the Raven's Coloured Progressive Matrices. Sch Psychol Int 22, 258.

56. Kigutha HN (1997) Assessment of dietary intake in rural communities in Africa: experiences in Kenya. Am J Clin Nutr 65, 1168 S-1172S

57. Steinfeld H (2003) Economic constraints on production and consumption of animal source foods for nutrition in developing countries. J Nutr 133, 4054S-4061S.

58. Brown DL (2003) Solutions exist for constraints to household production and retention of animal food products. $J$ Nutr 133, $4042 \mathrm{~S}-4047 \mathrm{~S}$ 
59. Allen L \& Ahluwalia N (1997) Improving Iron Status Through Diet: The Application of Knowledge Concerning Dietary Iron Bioavailability in Human Populations. Arlington, VA: OMNI Project.

60. Gibson RS, Yeudall F, Drost N, Mtitimuni B \& Cullinan T (1998) Dietary interventions to prevent zinc deficiency. Am J Clin Nutr 68, 484S-487S.
61. Gibson RS, Yeudall F, Drost N, Mtitimuni BM \& Cullinan TR (2003) Experiences of a community-based dietary intervention to enhance micronutrient adequacy of diets low in animal source foods and high in phytate: a case study in rural Malawian children. $J$ Nutr 133, 3992S-3999S 